\title{
Spectroscopic Investigation of Bis-Appended 1,2,3-Triazole Probe for the Detection of Cu(II) Ion
}

Debanjana Ghosh $^{\mathrm{a}}$, Shannon Rhodes ${ }^{\mathrm{a}}$, Domonique Winder ${ }^{\mathrm{a}}$, Austin Atkinson ${ }^{\mathrm{a}}$, Jaclyn Gibson $^{\mathrm{a}}$, Weihua Ming ${ }^{\mathrm{a}}$, Clifford Padgett ${ }^{\mathrm{b}}$, Shainaz Landge ${ }^{a}$, Karelle Aiken ${ }^{a *}$

\begin{abstract}
A novel bis-1,4-disubstituted-1,2,3-triazole chemosensor, accessed with "Click Chemistry", was probed for its recognition of metal ions. The interaction of the sensor with various cation analytes was investigated by ${ }^{1} \mathrm{H}-\mathrm{NMR}$, UV-Vis absorption and fluorescence spectroscopy. The bis-triazole is selective for $\mathrm{Cu}$ (II) with a detection limit in the micromolarconcentration range and a clear to yellow colorimetric response that is exclusive to that ion is observed. The stoichiometry of probe to $\mathrm{Cu}$ (II), 2 : 1, was determined with Job's plots based on titration studies using UV-absorption and ${ }^{1} \mathrm{H}-\mathrm{NMR}$ spectroscopy. Computational and spectroscopic investigations revealed that the sensor binds to $\mathrm{Cu}(\mathrm{II})$ via its triazole units.
\end{abstract}

Keywords: bis-triazole, copper(II), chemosensor, chemistry

\section{Introduction:}

Considerable attention has been given to the rational design of small organic chemonsensors for metal ions, particularly heavy transition metals (HTMs). Structurally, ion sensing in these probes can occur through displacement reactions,(1) metal-promoted bond formation and cleavage,(2) and metal-chelator complexes.(3) With the metal-chelator complexes, the potential exists to "tune" the selectivity and sensitivity of the probes by (i) taking advantage of cation affinity for specific atoms and (ii) controlling the size of the binding site through the intentional placement of the coordinating moieties in the sensors.(3) In most cases, a chelate arises from covalent or coordinate bonds between the metal and donorfunctional groups containing sulfur, nitrogen and/ or oxygen atoms.(4)

Metal cations are of biological and ecological importance.(5-7) Copper, in particular, is the third most abundant heavy metal in the body. This metal has an average concentration of $100-150 \mu \mathrm{g} \mathrm{L}^{-1}$ in the blood under normal conditions(8) and it serves as a co-factor for many proteins and enzymes. $(9,10)$ As a result, copper is essential for important processes such as proper brain function;(11) the stabilization of collagen fibrils and increased elasticity of elastin; $(12,13)$ the maintenance of the natural, intracellular homeostasis of iron;(14) ATP biosynthesis;(15) and the production of melanin in the skin. $(16,17)$ Therefore, an under- or over-supply of copper can be harmful. For example, intracellular copper-deficiency causes Menkes syndrome while an overload of copper is implicated in Wilson's disease.(18) Both can be fatal. Additionally, copper has a role in the progression of neurodegenerative diseases such as Alzheimer's, Parkinson's and Prion's Diseases.(18-20) In these cases, copper is involved in plaque formation and the production of harmful reactive oxygen species (ROS). In light of the fact that copper is significant to many biological processes, selective and sensitive copper-chemosensors can greatly impact human health. For example, these sensors could be used for diagnostic purposes, to enhance understanding of the metal's role in various diseases, in the development of more effective treatments and to track copper ion levels in the environment.

Many challenges still exist in designing effective copper sensors. Like all metals, especially those of environmental and biological significance, it is important to develop sensors that are truly exclusive to one particular ion. Additionally, copper ions with their fluorescent-quenching properties makes the design of molecules that provide a "turn-on" colorimetric responses attractive.(21-23)

1,2,3-Triazoles have emerged as promising chelators for HTMs because they can act as nitrogen (N)-donors.(24-26) Many 1,2,3-triazole metal complexes have been probed for their suitability in metallo-supramolecular systems.(27) In general, triazole structures use their nitrogens to bind cations, and their $\mathrm{Csp}^{2}-\mathrm{H}$ proton to bind the anions. $(27,28)$ The triazo- ligands are often made using the Click reaction, 1,3-dipolar $\mathrm{Cu}(\mathrm{I})$ catalyzed alkyne-azide cycloaddition (CuAAC), which is a simple, high yielding and atom economical process.(29) Previous work with bis-triazoles has targeted cation sensing, particularly HTMs.(11, 30-42) A number of studies have employed a "turn-off" response, taking advantage of fluorescence quenching properties of metals such as $\mathrm{Ni}^{2+}, \mathrm{Ag}^{+}, \mathrm{Pb}^{2+}$, $\mathrm{Hg}^{2+}$ and of course, $\mathrm{Cu}^{2+} .(30-34,37,39-41)$ With respect to $\mathrm{Cu}^{2+}$, there are less reports for bis-triazole sensors that provide a colorimetric signal.(43) Additionally, in many instances the bistriazole sensors fail to respond exclusively to $\mathrm{Cu}$ (II).(31, 34, 37, 38)

Herein, we report the synthesis of a novel bis-1,2,3triazole sensor appended with phenolic groups, (2,2-bis((1-)(2hydroxyphenyl)-1H-1,2,3-triazol-4-yl)methyl)-5,5-

dimethylcyclohexane-1,3-dione) (BPT) (Scheme 1). BPT exhibits a selective colorimetric response to copper(II), clear to yellow. To verify the selectivity, BPT was screened against an series of metal ions $\left(\mathrm{Fe}^{3+}, \mathrm{Fe}^{2+}, \mathrm{Cu}^{2+}, \mathrm{Ag}^{+}, \mathrm{Cr}^{3+}, \mathrm{Al}^{3+}, \mathrm{Co}^{2+}, \mathrm{Ni}^{2+}, \mathrm{Cd}^{2+}, \mathrm{Zn}^{2+}, \mathrm{Mg}^{2+}\right.$, $\mathrm{Li}^{+}$). Spectroscopic investigations with Nuclear Magnetic Resonance Spectroscopy (NMR), UV-absorption and fluorescence spectroscopy quantified the molecule's response to each cation. Additionally, computational studies along with NMR titration investigations were used to determine the $\mathrm{Cu}(\mathrm{II})$ binding site in BPT. Overall, our results reveal the existence of a $2: 1$ metal coordination complex for BPT : $\mathrm{Cu}^{2+}$ and provide insight into the structural characteristics of BPT that are important for metal-chelation.

\section{Experimental: \\ 2.1 Materials and methods}


All chemicals and reactants including the starting material for BPT synthesis and the perchlorate salts of metal ions were obtained from commercially available sources and used without further purification. Column Chromatography was performed with Selecto Scientific Si-gel (particle size 100-200 microns). Melting points were measured with Vernier Melt Station using Vernier LabQuest 2 and are uncorrected. High Resolution MS (HRMS) analyses were performed using MALDI, Q-TOF micro, 3200API, LCMS, GCMS EI (DI).

NMR spectra were recorded on Agilent MR400DD2 spectrometer, with a multinuclear probe with two RF channels and variable temperature capability: ${ }^{1} \mathrm{H}-\mathrm{NMR}$ : $400 \mathrm{MHz}$ and ${ }^{13} \mathrm{C}-\mathrm{NMR}$ : $100 \mathrm{MHz}$. The NMR solvent, DMSO-D6 ((CD $\left.)_{2} \mathrm{SO}\right)$, was purchased from Acros Organics. The reference was set for residual $\left(\mathrm{CH}_{3}\right)_{2} \mathrm{SO}$ at $2.50 \mathrm{ppm}$ for ${ }^{1} \mathrm{H}-\mathrm{NMR}$ and $30.37 \mathrm{ppm}$ for ${ }^{13} \mathrm{C}-\mathrm{NMR}$. The NMR signals were reported in parts per million ( $\mathrm{ppm}$ ) relative to the residual solvent and were described with multiplicity, singlet $(s)$, doublet $(d)$, triplet $(t)$, triplet of doublet $(t d)$, quartet $(q)$ and multiplet $(\mathrm{m})$; coupling constants $(\mathrm{J} ; \mathrm{Hz})$ and integration.

Room temperature absorption and steady state fluorescence measurements were performed using a Shimadzu UV2450 spectrophotometer and PerkinElmer LS55 with well plate reader fluorimeter respectively. The concentration of BPT was kept

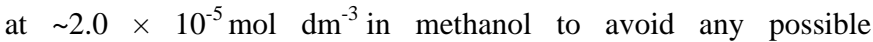
intermolecular effect. For the experiment in water, methanol has been used as a co-solvent in aqueous bulk. BPT in aqueous solution was prepared by adding BPT (methanol) to water in the ratio of 1:60 (v/v). Individual stock concentrations of $\sim 5.0 \times 10^{-3} \mathrm{~mol} \mathrm{dm}^{-3}$ for the perchlorate salts of metal ions were also prepared in methanol and deionized (D. I.) water. The methanol was HPLC grade. All the experiments are performed at ambient temperature $\left(27^{\circ} \mathrm{C}\right)$ with airequilibrated solutions.

A colourless crystal of BPT having the approximate dimensions of $0.2 \mathrm{~mm} \times 0.2 \mathrm{~mm} \times 0.2 \mathrm{~mm}$ was obtained by slow evaporation of DMSO and mounted on a glass fiber. All measurements were made on a Rigaku XtaLAB mini diffractometer using graphite monochromatic $\mathrm{Mo}_{\mathrm{\alpha}} \mathrm{K}_{\alpha}$ radiation at low temperature $\left(-100{ }^{\circ} \mathrm{C}\right)$.

\subsection{General procedure for synthesis of BPT (Scheme 1)}

2-Azidophenol(44) (718 mg, $5.32 \mathrm{mmol})$ and 5,5-dimethyl-2,2bis(2-propynyl)-1,3-cyclohexanedione(45) (501 mg, $2.31 \mathrm{mmol}$ ) were suspended in tert-butanol/water $(53 \mathrm{~mL} ; 1: 1, \mathrm{v} / \mathrm{v})$ in a round bottomed flask. The reaction was then heated for 15-20 min to allow the reactants to fully dissolve. An aqueous solution of copper(II) sulfate pentahydrate $(57.7 \mathrm{mg}, 0.23 \mathrm{mmol}$ in $5.0 \mathrm{~mL}$ of water) was added dropwise, followed by sodium ascorbate (463 mg, 2.31 $\mathrm{mmol})$. The reaction was vigorously stirred while refluxing for 18 hours. Upon cooling to room temperature, the resulting mixture was placed in an ice bath and diluted with cold D. I. water $(\sim 50 \mathrm{~mL})$ to induce precipitation. The crude, solid product was collected with vacuum filtration and subjected to thorough washing with D. I. water followed by ethyl acetate to yield an off-white/beige powder, 390 $\mathrm{mg}(33 \%)$.

M.P. $230.8-234.0^{\circ} \mathrm{C}$.

${ }^{1} \mathbf{H}$ NMR $\left(400 \mathrm{MHz},\left(\mathrm{CD}_{3}\right)_{2} \mathrm{SO}\right) \delta 10.53$ (broad $\left.s, \mathrm{OH}\right), 8.15(s, 2-$ $\mathrm{H}), 7.58(d d, 2-\mathrm{H}, 1.6,7.9 \mathrm{~Hz}), 7.31(t d, 2-\mathrm{H}, 1.6,7.8 \mathrm{~Hz}), 7.09$ (dd, 2-H, 0.94, 8.2 Hz), 6.96 ( $t d, 2-\mathrm{H}, 1.0,7.8 \mathrm{~Hz}), 3.29$ (s, 4-H), $2.77(s$, 4-H), $0.89(s, 6-\mathrm{H})$.

${ }^{13}$ C NMR $\left(101 \mathrm{MHz},\left(\mathrm{CD}_{3}\right)_{2} \mathrm{SO}\right) \delta$ 208.1, 149.6, 142.1, 130.2, 125.6, 125.1, 124.9, 119.9, 117.5, 68.5, 51.2, 30.9, 30.2, 28.8.

HRMS $(\mathrm{M}+\mathrm{H})^{+}$for $\mathrm{C}_{26} \mathrm{H}_{27} \mathrm{~N}_{6} \mathrm{O}_{4}$ : calculated $=487.2075$, found $=$ 487.2061. (see ESI, $\uparrow$ Fig. S11)

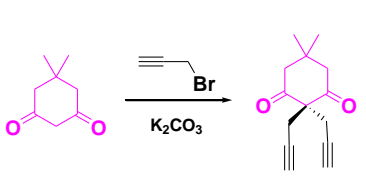

Scheme 1. Synthesis of probe BPT (2,2-bis((1-(2-hydroxyphenyl)$1 H$-1,2,3-triazol-4-yl)methyl)-5,5-dimethylcyclohexane-1,3-dione) (BPT).

\section{Results and Discussion:}

BPT was subjected to single crystal X-ray analysis. The sensor and its interaction with various metal ions were fully characterized with NMR (1D and 2D), UV-Vis absorption, and fluorescence spectroscopy. Complimentary computational experiments were undertaken to verify the structural properties of the probe that are important in $\mathrm{Cu}^{2+}$ detection.

\subsection{X-ray Structure Determination}

BPT crystallized in the orthorhombic space group P $22_{1} 2_{1} 2_{1}$ (\#19) with the unit cell parameters $\mathrm{a}=7.3216(6) \AA, \mathrm{b}=12.0506(9)$ $\AA$ and $\mathrm{c}=27.584(3) \AA$ (Table 1, see ESI, $\uparrow$ Tables 1-3 and Figs. S1214). The structure was collected at $173 \mathrm{~K}$ and had an unweighted $\mathrm{r}$ factor of $4.35 \%\left(\mathrm{R}_{1}\right)$. Figure 1 shows the single-crystal structure of BPT. The structure is held together to two independent hydrogen bonding chains with $\mathrm{H}$-bonds between the phenolic $\mathrm{O}-\mathrm{H}$ and triazole nitrogen of neighboring molecules. The first chain runs parallel to the a-axis, the second runs parallel to the b-axis (Figs. $2 \& 3$ ). Combined, these form a network of hydrogen bonds that hold the structure together.

Table 1. Crystallographic Data for BPT

\begin{tabular}{|c|c|}
\hline Compounds & BPT \\
\hline Empirical formula & $\mathrm{C}_{26} \mathrm{H}_{26} \mathrm{~N}_{6} \mathrm{O}_{4}$ \\
\hline Formula weight & 486.53 \\
\hline Temperature $(\mathrm{K})$ & 173 \\
\hline Crystal system & Orthorhombic \\
\hline Space Group & $\mathrm{P} 2{ }_{1} 2_{1} 2_{1}$ \\
\hline$a(\AA)$ & $7.3216(6)$ \\
\hline$b(\AA)$ & $12.0506(9)$ \\
\hline$c(\AA)$ & $27.584(3)$ \\
\hline$\alpha\left(^{\circ}\right)$ & 90 \\
\hline$\beta\left(^{\circ}\right)$ & 90 \\
\hline$\gamma\left({ }^{\circ}\right)$ & 90 \\
\hline Volume $\left(\AA^{3}\right)$ & $2433.7(4)$ \\
\hline
\end{tabular}




\begin{tabular}{|c|c|}
\hline$Z$ & 4 \\
\hline $\mathrm{D}_{\text {cal }}\left(\mathrm{g} \mathrm{cm}^{-3}\right)$ & 1.328 \\
\hline$\mu\left(\mathrm{mm}^{-1}\right)$ & 0.09 \\
\hline $\mathrm{F}(000)$ & 1024.0 \\
\hline Crystal Size $\left(\mathrm{mm}^{3}\right)$ & $0.20 \times 0.20 \times 0.20$ \\
\hline$\theta$ Range for data collection $\left.{ }^{\circ}\right)$ & $2.8-27.50$ \\
\hline & $-9 \leq \mathrm{h} \leq 9$ \\
\cline { 2 - 2 } Index ranges & $-15 \leq \mathrm{k} \leq 15$ \\
\cline { 2 - 2 } & $-35 \leq 1 \leq 35$ \\
\hline Reflections Collected & 26,095 \\
\hline Restraints / parameters & $0 / 325$ \\
\hline Goodness-of-fit on $\mathrm{F}^{2}$ & 1.10 \\
\hline Final R indexes [I $>2 \sigma(\mathrm{I})]$ & $\mathrm{R}_{1}=0.044 \quad \mathrm{wR}_{2}=0.100$ \\
\hline Final R indexes [all data] & $\mathrm{R}_{1}=0.0543 \quad \mathrm{wR}_{2}=0.100$ \\
\hline Largest diff. peak and hole $\left(\mathrm{e} \AA^{-3}\right)$ & 0.17 and -0.23 \\
\hline
\end{tabular}

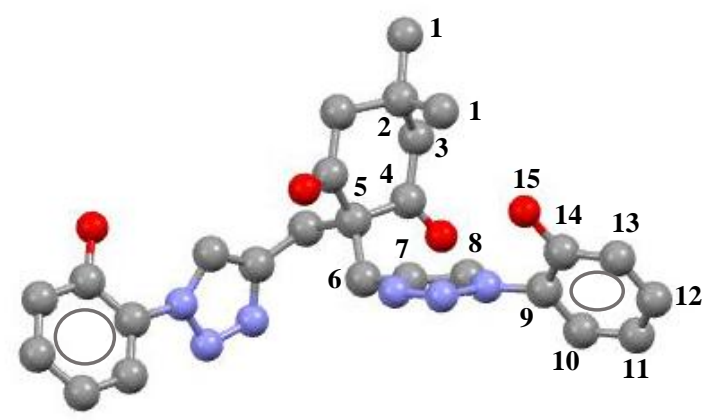

Figure 1: A displacement ellipsoid plot for BPT (50\% probability; hydrogen atoms removed for clarity).

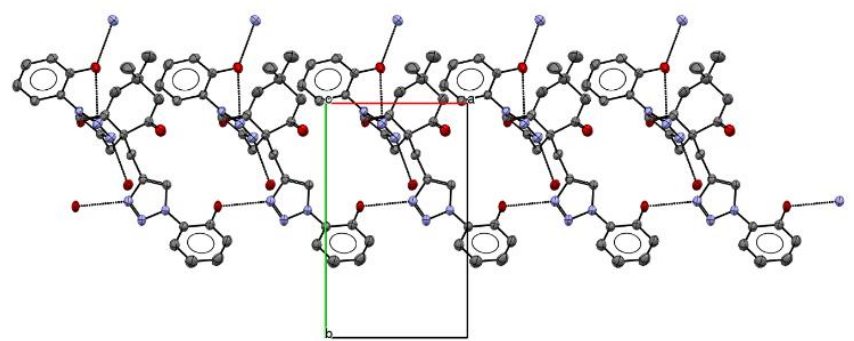

Figure 2: A single of layer of the unit cell viewed down the c-axis highlighting the hydrogen bonding motif that runs parallel to the aaxis.

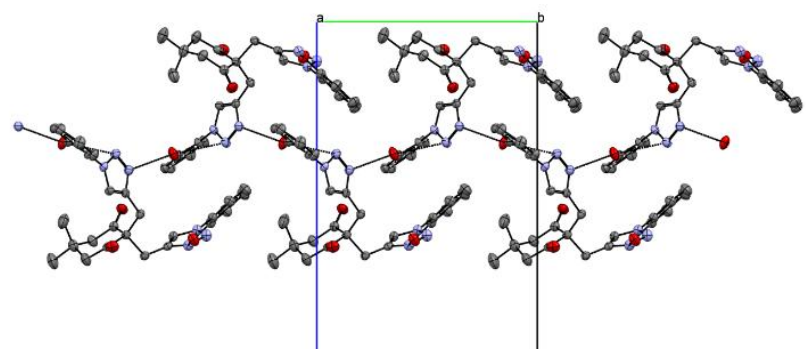

Figure 3: A single of layer of the unit cell viewed down the a-axis highlighting the hydrogen bonding motif that runs parallel to the baxis.

\subsection{NMR Studies}

The binding behavior of BPT was explored with various cations via NMR spectroscopy in deuterated DMSO (DMSO-D6). The ${ }^{1} \mathrm{H}$ NMR spectrum of BPT (see ESI, $\uparrow$ Fig. S1) showed the distinctive triazole $\mathrm{Csp}^{2}-\mathrm{H}$ singlet at $8.15 \mathrm{ppm}$. This singlet is easily distinguished from other signals in the aromatic region. For that particular reason, changes in the triazole $\mathrm{Csp}^{2}-\mathrm{H}$ peak position upon addition of analytes has been exploited in many applications(46-48) and in our studies as well.(28) The phenolic -OH appears in the region of $\delta 10.53 \mathrm{ppm}$ as a broadened singlet. The rest of the aromatic region from $\delta 6.94-7.59 \mathrm{ppm}$ and the aliphatic protons from $\delta 0.80-3.40 \mathrm{ppm}$ show the expected coupling patterns. The ${ }^{13} \mathrm{C}$ NMR experiments for BPT (see ESI, $\dagger$ Fig. S2) gave the signals in the anticipated regions; the aliphatic ranging from $\delta 28.8-68.5$ $\mathrm{ppm}$ and the aromatic from $\delta 117.5-150.0 \mathrm{ppm}$. The carbonyls of cyclohexanedione resonate at 208.1 ppm. COSY and HSQC experiments were used to assist with making full assignments for proton and carbon signals, respectively (see ESI, $\dagger$ Fig. S3, S4a and $\mathrm{S} 4 \mathrm{~b})$. It should be noted that ${ }^{1} \mathrm{H}$ and ${ }^{13} \mathrm{C}$ NMR spectra for BPT in deuterated methanol are similar to those with DMSO-D6.

The Nuclear Overhauser Effect (NOE) experiments were carried out to determine the conformation of BPT in solution before chelation (see ESI, $\uparrow$ Fig. S5). More specifically, investigations probed a possible correlation between the triazole $\mathrm{Csp}^{2}-\mathrm{H}$ and phenolic $\mathrm{Csp}^{2}-\mathrm{H}$ ortho to the axial bond. In our previous work with PTP (2-(4-phenyl-1-H-1,2,3-triazol-1-yl) phenol), a mono-triazole sensor, it was clearly indicated that the triazole proton was in close proximity to that region (Fig. 4).(28) However, with the present bistriazole appended derivative we did not observe any interaction (Fig. 4). In the single X-ray crystal structure for BPT the triazole $\mathrm{Csp}^{2}-\mathrm{H}$ proton is on the same side as the phenolic oxygen (Fig. 1). It is likely that the molecule retains this conformation in solution as well.

(A)
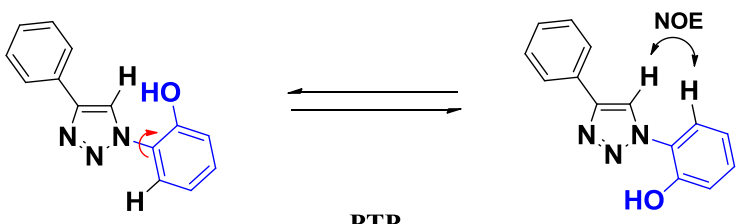

PTP

observed

(B)

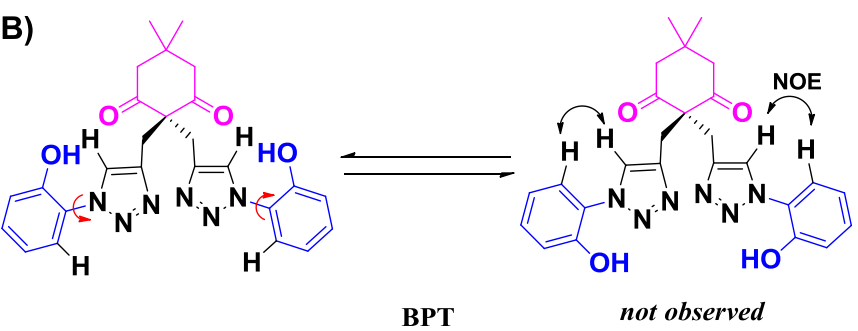

Figure 4. NOESY correlation for (A): PTP(28) and (B): BPT

To gain insight into BPT's interaction with copper(II) and other ions, ${ }^{1} \mathrm{H}$ NMR experiments were conducted with selected cations $\left(\mathrm{Zn}^{2+}, \mathrm{Cu}^{2+}, \mathrm{Fe}^{2+}, \mathrm{Ag}^{+}, \mathrm{Al}^{3+}, \mathrm{Co}^{2+}, \mathrm{Ni}^{2+}\right)$ (Fig. 5). The sensor, 
in deuterated dimethyl sulfoxide, was treated with equivalent amounts of the metal salts. Signals for the triazole, the -OH and other phenolic protons were monitored for changes. The -OH signal which appears at $10.53 \mathrm{ppm}$ sharpens immediately upon addition of each cation suggesting that the hydroxyl group is significantly affected.(49, 50) With the exception of $\mathrm{Cu}^{2+}$, inappreciable changes were observed for the triazole $\mathrm{Csp}^{2}-\mathrm{H}$ and phenolic $\mathrm{Csp}^{2}-\mathrm{H}$ 's. Copper(II) showed a significant downfield shift for the triazole $\mathrm{Csp}^{2}-\mathrm{H}$ and $\mathrm{O}-\mathrm{H}, 8.15$ to $8.63 \mathrm{ppm}(\Delta \delta=0.48 \mathrm{ppm})$ and $10.53 \mathrm{ppm}$ to $10.78 \mathrm{ppm}(\Delta \delta=0.22 \mathrm{ppm})$, respectively (Fig. 5). In addition, $\mathrm{Cu}^{2+}$ was the only cation with which observable changes were noted for the phenolic $\mathrm{Csp}^{2}-\mathrm{H}$ 's signals which were shifted downfield as well. Overall, results from this experiment demonstrated that the probe selectively binds to $\mathrm{Cu}^{2+}$ and that the triazole and phenolic groups participate in that binding.

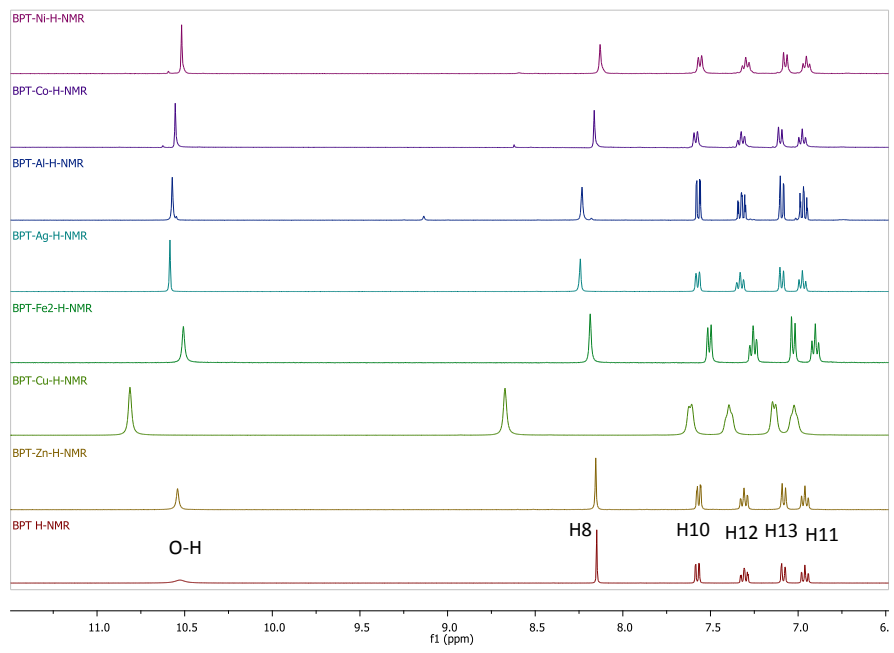

Figure 5. Changes in partial ${ }^{1} \mathrm{H}$ NMR (400 MHz) spectra of BPT $\left(\sim 1.0 \times 10^{-2} \mathrm{~mol} \mathrm{dm}^{-3}\right)$ and of BPT upon addition of equivalent amount of selected cations $\left(\mathrm{Zn}^{2+}, \mathrm{Cu}^{2+}, \mathrm{Fe}^{2+}, \mathrm{Ag}^{+}, \mathrm{Al}^{3+}, \mathrm{Co}^{2+}, \mathrm{Ni}^{2+}\right)$ in DMSO-D6.

Titration experiments with BPT and $\mathrm{Cu}^{2+}$ using ${ }^{1} \mathrm{H}$ NMR spectroscopy further supported the importance of the triazole and the phenolic groups in binding (Fig. 6). Importantly, the downfield shift of the triazole $\mathrm{Csp}^{2}-\mathrm{H}$ signal was proportional to the equivalents of $\mathrm{Cu}^{2+}$. This trend indicated that the triazole group is a N-donor during chelation.(51) The $\Delta \delta$-triazole $\mathrm{Csp}^{2}-\mathrm{H}$ was applied in a Job's plot. A curve maximum at $\sim 0.66$ revealed a $2: 1$ binding interaction, BPT : $\mathrm{Cu}^{2+}$ (see ESI, $\uparrow$ Fig. S6). Beyond a certain point, signal broadening due to a paramagnetic effect overwhelmed the spectrum with increasing equivalents of copper(II).(52)
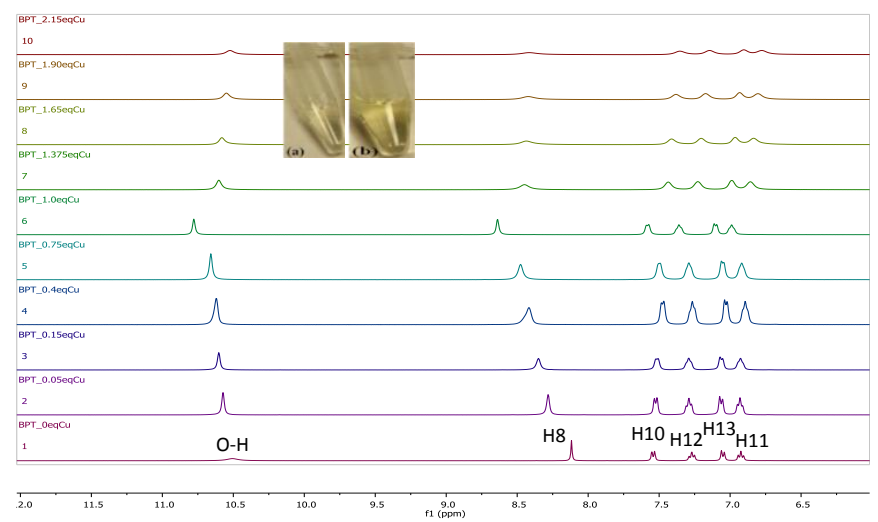

Figure 6. Changes in partial ${ }^{1} \mathrm{HNMR}(400 \mathrm{MHz})$ spectra of BPT $\left(\sim 7.8 \times 10^{-2} \mathrm{~mol} \mathrm{dm}^{-3}\right)$ upon increasing equivalents of $\mathrm{Cu}(\mathrm{II})$ perchlorate salt in DMSO-D6. Image for colorimetric detection of (a) BPT sensor $\left(\sim 1 \times 10^{-2} \mathrm{~mol} \mathrm{dm}^{-3}\right)$ and (b) BPT sensor and $\mathrm{Cu}(\mathrm{II})$ ion $\left(2 \times 10^{-2} \mathrm{~mol} \mathrm{dm}^{-3}\right)$ in $\mathrm{MeOH}$ (inset).

\subsection{Steady state studies}

BPT showed a colorimetric response with $\mathrm{Cu}$ (II) (Fig. 6 inset \& see ESI, $\uparrow$ Fig. S10). The faint yellow tinge of the probe in methanol solution deepens in intensity (bright yellow) after addition of copper salt to the sensor. Color was also observed with $\mathrm{Fe}^{3+}, \mathrm{Fe}^{2+}$, and $\mathrm{Cr}^{3+}$ ions (see ESI, $\uparrow$ Fig. S10). However, this was a result of the original perchlorate salt solutions and not because of binding interaction of the metals with the probe. To quantify this sensing performance, the steady state photophysical properties of the BPT by itself and in the presence of various cations were first investigated using absorption and fluorescence spectroscopy in methanol owing to higher solubility of BPT in this solvent (Fig. 7).

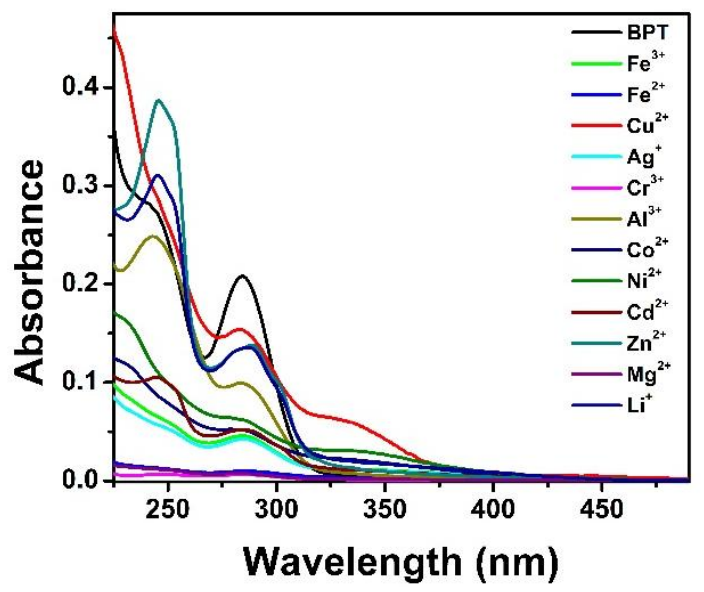

Figur e 7.

Absorption spectral variation of BPT $\left(\sim 2 \times 10^{-5} \mathrm{~mol} \mathrm{dm}^{-3}\right)$ with the addition of $4.0 \times 10^{-4} \mathrm{~mol} \mathrm{dm}^{-3}$ of metal perchlorate salts in methanol. 
Compared to all other metal ions, the characteristic absorption spectrum of BPT displayed a far greater response to copper (Fig. 7, see ESI, $\uparrow$ Fig. S7). Baseline correction with each metal salt was performed to negate the absorption due to molecular relaxation (e.g. $\mathrm{Li}^{+}$) or $d$ - $d$ splitting of the transition metal ions, if any. $(53,54)$ The absorption spectrum of BPT showed the lowest energy absorption maximum at $285 \mathrm{~nm}$ in methanol, the $\pi-\pi *$ transition of the triazole substituted phenol rings (Fig. 7).(28, 55-57) Appearance of a new band at $330 \mathrm{~nm}$ was prominent upon addition of the copper(II) salt. Enhanced absorbance was also observed with the addition of $\mathrm{Ni}^{2+}$ and $\mathrm{Co}^{2+}$. However, competition experiments clearly demonstrated a selectivity for $\mathrm{Cu}^{2+}$ over all other ions and NMR studies showed no change in the BPT chemical shifts when $\mathrm{Ni}^{2+}$ and $\mathrm{Co}^{2+}$ were added (Figs. $5 \& 9$ ). This confirmed that the enhanced absorbance with $\mathrm{Ni}^{2+}$ and $\mathrm{Co}^{2+}$ resulted from a contribution from the absorption of the perchlorate salts and not binding.

Screening experiments were also performed in aqueous medium (Fig. 8). As in methanol, BPT showed selectivity for $\mathrm{Cu}^{2+}$. However, notably, the distinctive response to $\mathrm{Cu}^{2+}$ was more prominent in water. Upon addition of copper perchlorate a new charge transfer band developed around $340 \mathrm{~nm}$. This band was $\sim 10$ $\mathrm{nm}$ red-shifted from that in methanol $(\sim 330 \mathrm{~nm})$ due to the enhanced solvent polarity in water. Overall, results from both the aqueous and methanol media studies point to the same binding mechanism for the probe with copper ions.

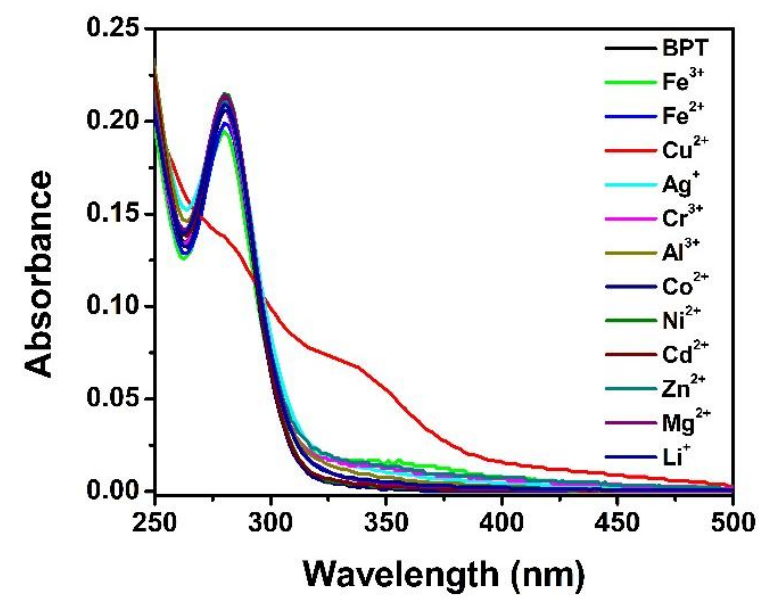

Figure 8. Absorption spectral variation of BPT $\left(\sim 2 \times 10^{-5} \mathrm{~mol} \mathrm{dm}^{-3}\right)$ with the addition of $4.0 \times 10^{-4} \mathrm{~mol} \mathrm{dm}^{-3}$ of metal perchlorate salts in water.

Competition experiments were performed to evaluate the practical use of the sensor. These experiments were carried out in both methanol and water (Fig. 9). Treated separately with 1 equivalent of $\mathrm{Cu}^{2+}$ ions in presence of 20 equivalents of other interfering metal ions $\left(\mathrm{Fe}^{3+}, \mathrm{Fe}^{2+}, \mathrm{Ag}^{+}, \mathrm{Cr}^{3+}, \mathrm{Al}^{3+}, \mathrm{Co}^{2+}, \mathrm{Ni}^{2+}, \mathrm{Cd}^{2+}\right.$, $\mathrm{Zn}^{2+}, \mathrm{Mg}^{2+}$ and $\mathrm{Li}^{+}$), BPT demonstrated remarkable selectivity for $\mathrm{Cu}^{2+}$. Other cations did not interfere with BPT's detection of $\mathrm{Cu}^{2+}$.
Furthermore, compared to methanol, the molecule showed enhanced sensitivity to copper(II) over other cations in aqueous medium (Fig. $9 b)$.
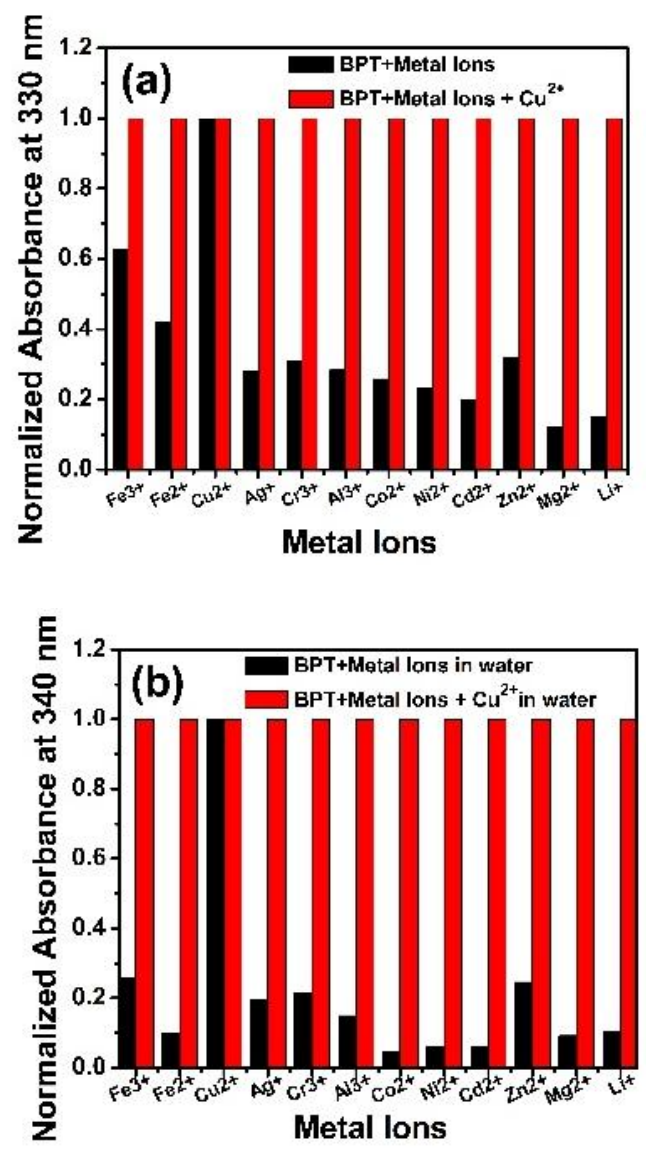

Figure 9. Metal ion selectivity towards BPT $\left(\sim 2 \times 10^{-5} \mathrm{~mol} \mathrm{dm}^{-3}\right)$ through absorption study in (a) methanol and (b) water. The black bars indicate the normalized absorption of BPT in presence of $\sim 4 \times$ $10^{-4} \mathrm{~mol} \mathrm{dm}^{-3}$ of various metal ions. The red bars represent the normalized absorption of BPT with the addition of $\sim 2 \times 10^{-5} \mathrm{~mol}$ $\mathrm{dm}^{-3}$ copper(II) perchlorate in presence of other metal ions.

To further investigate the sensitivity of BPT towards $\mathrm{Cu}^{2+}$, titration with various concentrations of copper ions was performed in methanol because of the molecule's higher solubility in this solvent. Subsequent addition of copper(II) perchlorate to BPT induced a gradual lowering of the lowest energy absorption band at $285 \mathrm{~nm}$ with a concomitant development of a new band around $330 \mathrm{~nm}$ (Fig. 10). Emergence of a new lower energy absorption band indicated relaxation of the conjugated electron network. This increases the possibility for charge transfer between BPT and the $\mathrm{Cu}^{2+}$ ions. Importantly, the presence of two well-defined isosbestic points at $272 \mathrm{~nm}$ and $298 \mathrm{~nm}$ indicated the formation of a unique complex between the probe and $\mathrm{Cu}^{2+}$.(58-60) This experiment showed the low detectable limit of $\mathrm{Cu}^{2+}$ with BPT in the submicromolar range of $\sim 2$ $\times 10^{-6} \mathrm{~mol} \mathrm{dm}^{-3}$. This is much lower than its toxic level, $20 \mu \mathrm{g} / \mathrm{g}$, or 
the recommended concentration of copper(II) ion in drinking water,

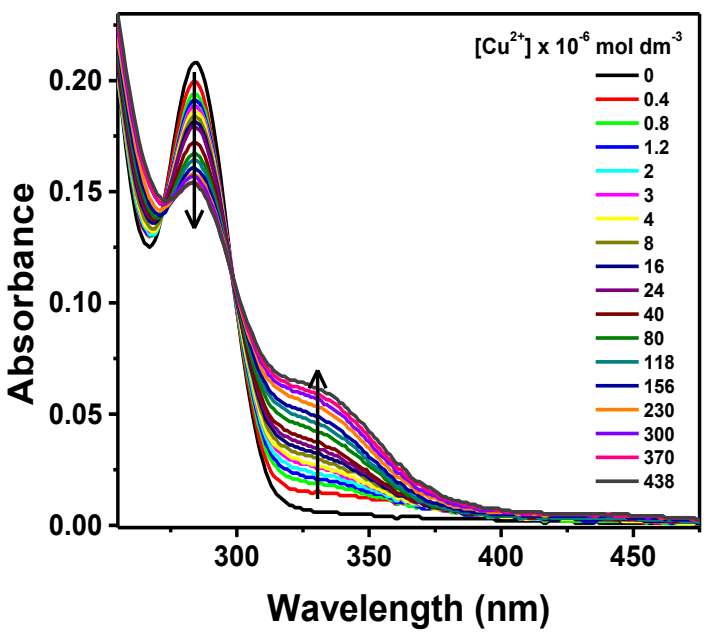

Figure 10. Absorption spectral variation of BPT $\left(\sim 2 \times 10^{-5} \mathrm{~mol} \mathrm{dm}^{-}\right.$ $\left.{ }^{3}\right)$ with the addition of Copper perchlorate hexahydrate in methanol. Copper salt concentrations are provided in the legends.

The stoichiometry of BPT with $\mathrm{Cu}^{2+}$ was determined with Job's plot using the absorption band at $330 \mathrm{~nm}$ (Fig. 11). The graph was plotted between the difference in the absorbance, $\Delta \mathrm{A}=\mathrm{A}_{\mathrm{x}}-\mathrm{A}_{0}$, and the mole fraction, $[\mathbf{B P T}] /\left[\mathbf{B P T}+\mathrm{Cu}^{2+}\right]$. The curve, fitted with the non-linear fit parameter of ORIGIN 8.0 software, had a maximum at 0.65. This indicated a 2:1 stoichiometric complex, BPT : $\mathrm{Cu}^{2+}$, consistent with results of the ${ }^{1} \mathrm{H}-\mathrm{NMR}$ Job's plot (see ESI, $\dagger$ Fig. S6).(58)

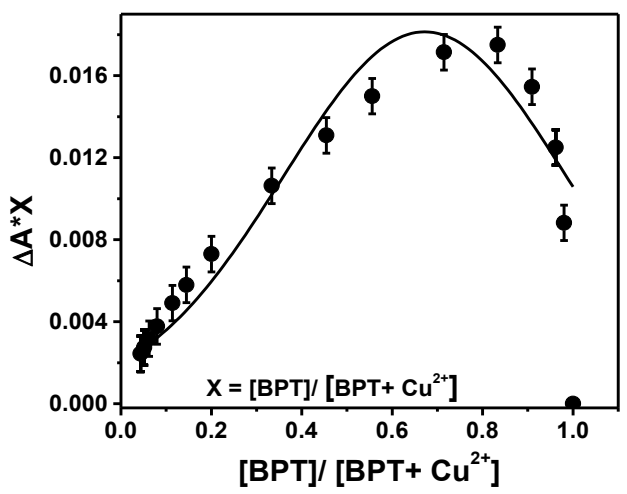

Figure 11. Job's plot of BPT with Copper(II) perchlorate hexahydrate in methanol. The absorbance was monitored at $330 \mathrm{~nm}$.

Further insight into the stoichiometry of the complex formed and binding of the probe with copper ions was gained from the Benesi-Hildebrand method following the modified equation (Eq.1) from the absorption data:(28, 62-64)

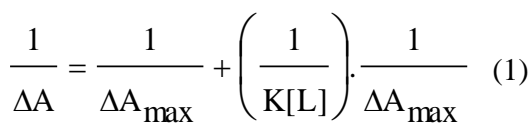

$$
\Delta \mathrm{A}=\mathrm{A}_{\mathrm{x}}-\mathrm{A}_{0} \text { and } \Delta \mathrm{A}_{\max }=\mathrm{A}_{\infty}-\mathrm{A}_{0} ;
$$

where, $\mathrm{A}_{0}, \mathrm{~A}_{\mathrm{x}}$ and $\mathrm{A}_{\infty}$ are the absorbances of the probe (BPT) in the absence, at an intermediate concentration and at a concentration of complete interaction with copper ions at $330 \mathrm{~nm}$, respectively. $\mathrm{K}$ is the binding constant and [L] is the concentration of $\mathrm{Cu}^{2+}$.

The binding plot of $1 / \Delta \mathrm{A}$ against $1 /\left[\mathrm{Cu}^{2+}\right]$ depicted deviation from linearity at the higher concentrations of copper salt indicating the formation of $2: 1$ binding complex of BPT with $\mathrm{Cu}^{2+}$ (Fig. 12).(65) This substantiated the result obtained from Job's plot from both spectroscopic techniques.

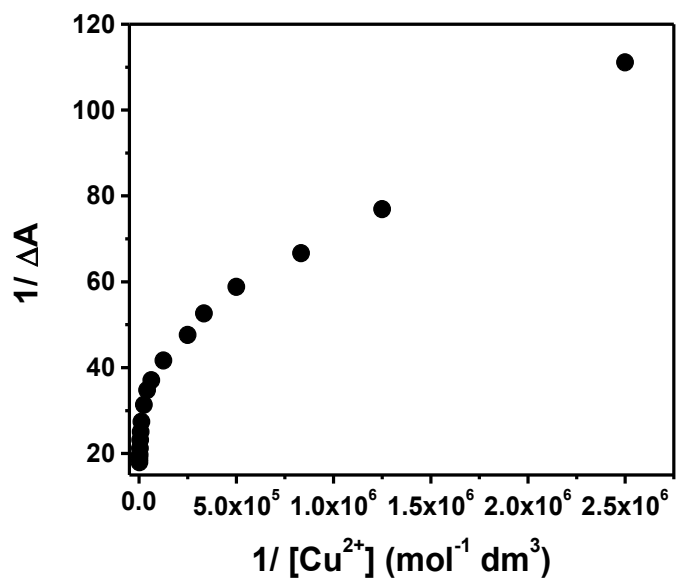

Figure 12. Benesi-Hildebrand plot of BPT with addition of Copper perchlorate hexahydrate showed deviation from linearity.

After studying the binding characteristics of copper(II) ions with BPT through steady state absorption, we shifted our interest to investigate the fluorescence of the probe with the metal ions. Photoexcitation of BPT at $290 \mathrm{~nm}$ yielded a broad emission band, $\lambda_{\max }=370 \mathrm{~nm}$, in methanol (Fig. 13). Successive addition of copper salt revealed gradual quenching of the probe's fluorescence. Different levels of fluorescence quenching were also observed with other metal ions (see ESI, $\uparrow$ Fig. S8). The fluorescence quenching governed by Stern-Volmer equation $\mathrm{F}_{0} / \mathrm{F}=1+\mathrm{K}_{\mathrm{SV}}\left[\mathrm{Cu}^{2+}\right]$ revealed a linearity of the corresponding plot (see ESI, $\uparrow$ Fig. S9). $\mathrm{F}_{0}$ and $\mathrm{F}$ are the fluorescence intensities in the absence and presence of the quencher, $\mathrm{Cu}^{2+}$, respectively. $\mathrm{K}_{\mathrm{SV}}$ is the Stern-Volmer quenching constant. The fluorescence was monitored at the emission maximum of BPT fluorescence. Slope of the plot yielded the $\mathrm{K}_{\mathrm{SV}}$ value as 6.96 $\times 10^{4} \mathrm{~mol}^{-1} \mathrm{dm}^{3}$ implying that the fluorescence quenching occurred because of binding of $\mathrm{Cu}$ (II) ion with BPT and not through diffusional collision between the two interacting species. 


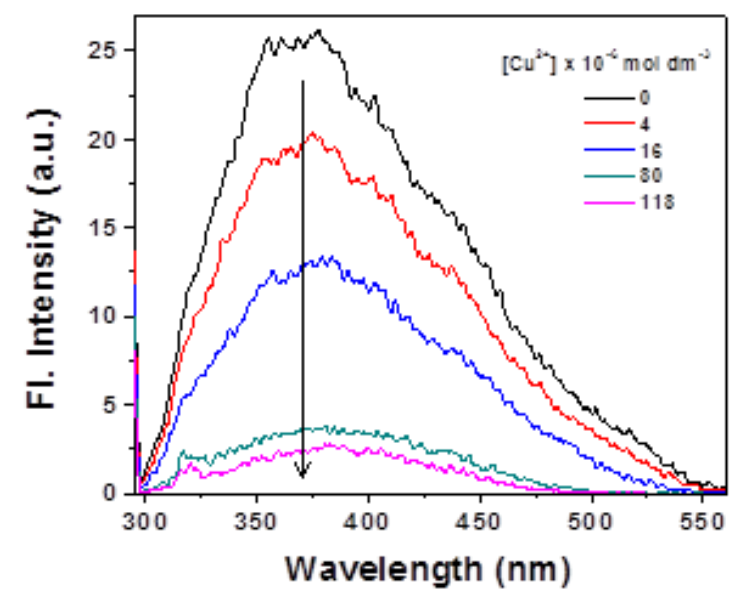

Figure 13. Fluorescence quenching of BPT $\left(\sim 2 \times 10^{-5} \mathrm{~mol} \mathrm{dm}^{-3}\right)$ with the addition of Copper perchlorate hexahydrate in methanol. Copper salt concentrations are provided in the legends.

\subsection{Computational Studies}

Based on the literature-precedent for the interaction of $\mathrm{Cu}$ (II) with triazole systems(27) and the current experimental results, plausible binding modes of BPT with $\mathrm{Cu}(\mathrm{II})$ were explored. For a thorough analysis, the conformation of BPT and various stoichiometric ratios of BPT : $\mathrm{Cu}^{2+}$ were investigated: sensor only (A), $1: 1\left(\mathbf{B}\right.$, sensor : $\left.\mathrm{Cu}^{2+}\right), 1: 2\left(\mathbf{C}\right.$, sensor : $\left.\mathrm{Cu}^{2+}\right)$ and $2: 1(\mathbf{D}$, sensor: $\mathrm{Cu}^{2+}$ ) (Scheme 2).

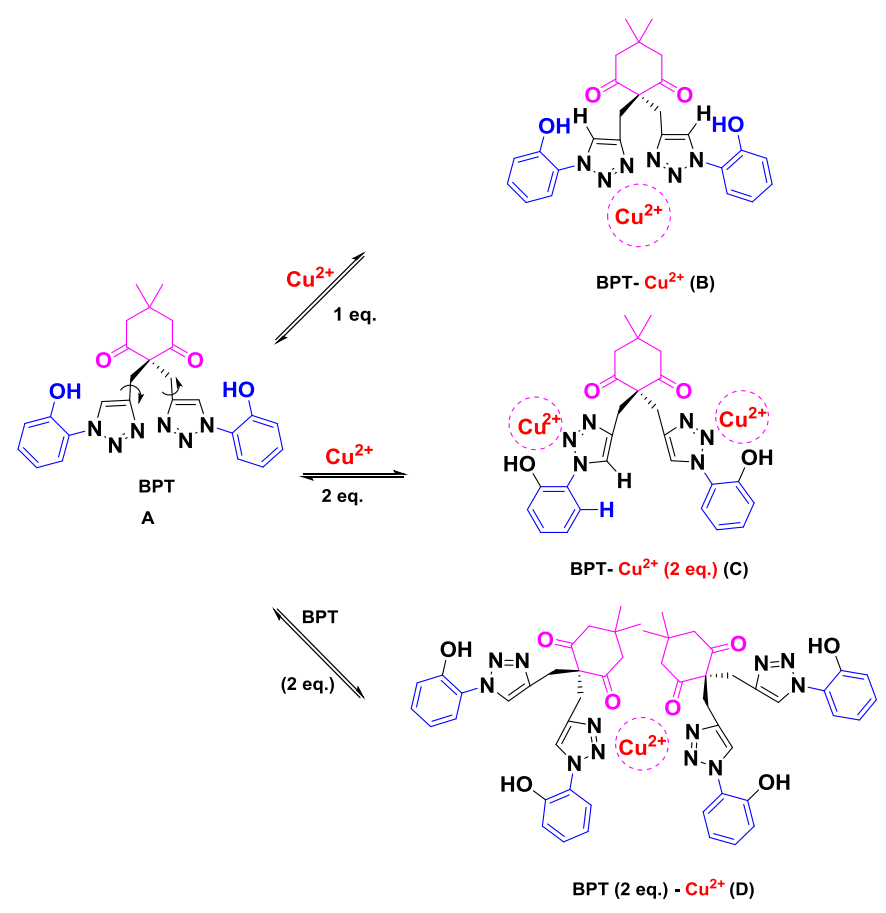

Scheme 2. The proposed binding mode of BPT and $\mathrm{Cu}^{2+}$ metal cation showing sensor : $\mathrm{Cu}^{2+}$ at $1: 1(\mathbf{B}) ; 1: 2(\mathbf{C})$ and $2: 1$ (D) binding mode.
The conformational analyses were performed with the semiempirical potential PM6 for A, B and C. MMFF was used for D. This study used the Spartan 2010 equilibrium conformer search algorithm, which examined 10000 conformers of each system.(66) The lowest energy conformation for each system was minimized in Gaussian 09W(67) using DFT-UB3LYP level of theory and the $6-31 \mathrm{G}^{*}$ basis set. Water was chosen as the solvent using the default implicit solvent model. The lowest energy conformation of each system is shown in Figure 14.

The lowest energy BPT conformation has the two triazole groups nearly planar with each other. Within each arm, the phenyl ring is planar with the triazole, and both arms have oxygen atoms pointing in the same direction, a position that would allow for intramolecular hydrogen bonding. In the actual X-ray structure, the triazole rings of each molecule are rotated $81^{\circ}$ with respect to each other and the phenyl ring is rotated $60^{\circ}$ with respect to the triazoles. In this case, each molecule interacts with four neighbouring molecules through intermolecular hydrogen bonding. This intermolecular interaction greatly affects the geometry in the solid state, thus the difference from the computationally-predicted conformer (Figs. 1-3).

For a 1:1 binding ratio with BPT and copper ion, structure $\mathbf{B}$, predicts binding with the triazole nitrogens (Scheme 2). For the 1 : 2 BPT : $\mathrm{Cu}^{2+}$ complex, the predicted lowest energy binding mode has both copper ions chelating with the triazole nitrogen atoms and the oxygen atoms of the phenols.

In the prediction for the $2: 1, \mathbf{B P T}: \mathrm{Cu}^{2+}$, binding interaction, the coordination of BPT to the metal at higher concentrations of copper occurs through interaction with the triazole nitrogens and carbonyl groups.

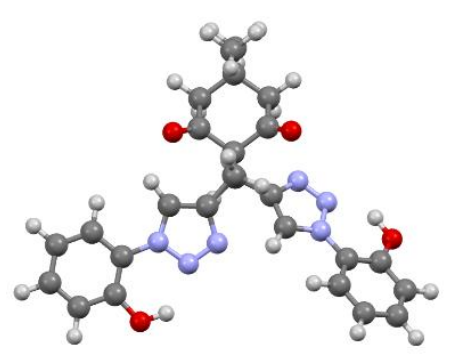

(A)

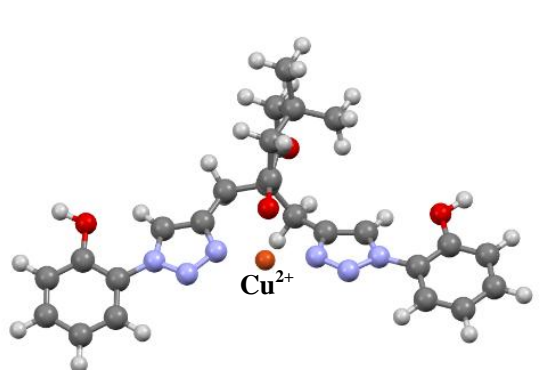

(B) 


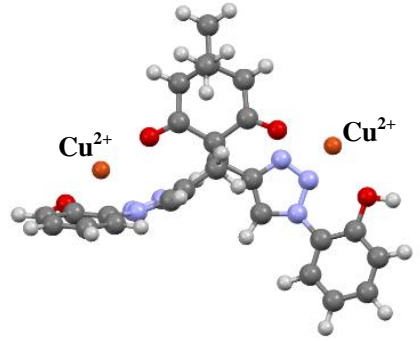

(C)

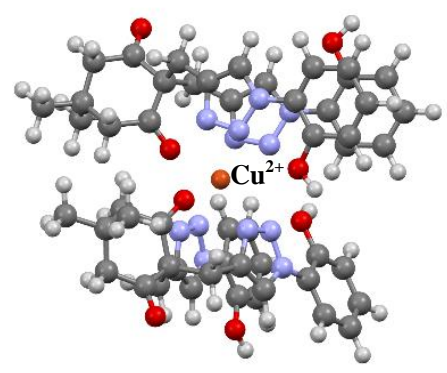

(D)

Figure 14. Lowest energy conformation for BPT (A), BPT with one $\mathrm{Cu}^{2+}$ ion $(\mathbf{B})$, BPT with two $\mathrm{Cu}^{2+}$ ion $(\mathbf{C})$, two BPT with one $\mathrm{Cu}^{2+}$ ion (D) from the conformational analysis.

Based on complex formation energies, calculations suggest that $1: 2(\mathbf{C})$ and $2: 1$ (D), BPT : $\mathbf{C u}^{2+}$, are possible (Table 2). Of the two, the values indicate that a binding mode of $2: 1$ (D) is most likely. Moreover, $\mathbf{D}$ predicts that $\mathrm{Cu}^{2+}$ resides in a cavity created between the triazole-phenol units, and that binding is via triazole $\mathrm{N}$-donation without the participation of the phenolic oxygen groups. This predicted probe-to-metal interaction is most consistent with results of the NMR titration studies and Job's plots (Figs. $3 \&$ 6, see ESI, $\dagger$ Fig. S6).

Table 2. Calculated Enthalpies of Formation

\begin{tabular}{|c|c|c|}
\hline Structure & BPT $: \mathbf{C u}^{2+}$ & complex E in $\mathbf{~ J J / m o l ~}$ \\
\hline $\mathrm{B}$ & $1: 1$ & -623.9 \\
\hline $\mathrm{C}$ & $1: 2$ & -777.2 \\
\hline $\mathrm{D}$ & $2: 1$ & -839.2 \\
\hline
\end{tabular}

\section{Conclusion}

An efficient, novel colorimetric bis-appended 1,2,3triazole sensor, BPT, was successfully synthesized in two steps using the "Click chemistry" approach. The sensor gave a colorimetric signal in the presence copper(II) ion, clear to yellow. NMR and UV-Vis absorption studies, including competition investigations (Fig. 9), revealed BPT's exclusive preference for binding $\mathrm{Cu}^{2+}$ over other cations. Notably, this selectivity and sensitivity is especially prominent in aqueous medium.

Two isosbestic points in absorption experiments proved the formation a new BPT- $\mathrm{Cu}^{2+}$ species. The triazole group is an $\mathrm{N}$ donor during binding as revealed by NMR and computational studies. Overall, Job's plots based on two different experiments, NMR and UV-vis spectroscopy, indicate a 2 : 1 , sensor : cation, stoichiometry. Computational studies suggest structure $\mathbf{D}$ as the most probable binding motif (Fig. 13). Thus, it is likely that the $\mathrm{Cu}^{2+}$ selectivity is achieved by the N-donating ability of the triazole groups in conjunction with the binding cavity formed between these triazole-phenol moeities.

Currently, our work focuses on synthesizing novel molecular sensors that can be applied to dual sensing $(\mathrm{pH}$, cation, anion), molecular switches, and logic gate applications. Studies on BPT's selective detection of $\mathrm{Cu}^{2+}$ has influenced the direction of this new work. Results reported here indicate that modifications can be made to the backbone of the molecule to enhance the signalling response, for example adding functional groups or aromatic moieties that provide a higher degree of conjugation in the molecule. However, the triazole-phenol unit, as is present in the structure of BPT, must be preserved to maintain selectivity and sensitivity for $\mathrm{Cu}^{2+}$.

\section{Supporting Information:}

CCDC 1449447 contains the supplementary crystallographic data for this paper. These data can be obtained free of charge via http://www.ccdc.cam.ac.uk/conts/retrieving.html (or from the Cambridge Crystallographic Data Centre, 12, Union Road, Cambridge CB2 1EZ, UK; fax: +44 1223 336033).

Supporting information for this work has been provided with the current manuscript.

\section{Acknowledgements}

The authors acknowledge the Department of Chemistry, Georgia Southern University (GSU), Honors Research Fund and the College Office of Undergraduate Research (COUR) for the financial assistance. DG and WM gratefully acknowledge the financial support from Office of Naval Research (Award number: N000141210589). JG, SL and KA greatly acknowledge the support of the National Science Foundation (Award Number: NSF-CHE (REU) 1359229). We thank Dr. Jeffrey Orvis for helpful discussions.

\section{References}

${ }^{a}$ Department of Chemistry, Georgia Southern University, 521 College of Education Drive, Statesboro, GA 30460-8064, USA.

${ }^{\mathrm{b}}$ Department of Chemistry and Physics, Armstrong Atlantic State University, 11935 Abercon Street, Savannah, GA 31419, USA.

Corresponding Author: Email: kaiken@georgiasouthern.edu and slandge@georgiasouthern.edu

1. Chen X, Chen W, Mulchandani A, Mohideen U. Application of displacement principle for detecting heavy metal ions 
and EDTA using microcantilevers. Sensors and Actuators B: Chemical. 2012;161(1):203-8.

2. Kaur K, Saini R, Kumar A, Luxami V, Kaur N, Singh P, et al. Chemodosimeters: An approach for detection and estimation of biologically and medically relevant metal ions, anions and thiols. Coordination Chemistry Reviews. 2012;256(17-18):1992-2028. 3. Lee D. Metal Chelation Chemistry. Chemosensors: John Wiley \& Sons, Inc.; 2011. p. 41-64.

4. Flora SJS, Pachauri V. Chelation in Metal Intoxication. International Journal of Environmental Research and Public Health. 2010;7:2745-88.

5. Anastassopoulou J, Theophanides T. The Role of Metal Ions in Biological Systems and Medicine. In: Kessissoglou D, editor. Bioinorganic Chemistry. NATO ASI Series. 459: Springer Netherlands; 1995 . p. 209-18.

6. Csavina J, Field J, Taylor MP, Gao S, Landázuri A, Betterton EA, et al. A review on the importance of metals and metalloids in atmospheric dust and aerosol from mining operations. Science of The Total Environment. 2012;433:58-73.

7. Tchounwou PB, Yedjou CG, Patlolla AK, Sutton DJ. Heavy Metals Toxicity and the Environment. EXS. 2012;101:13364.

8. O'Halloran TV, Culotta VC. Metallochaperones, an Intracellular Shuttle Service for Metal Ions. Journal of Biological Chemistry. 2000;275(33):25057-60.

9. Harris ED. Copper as a cofactor and regulator of copper,zinc superoxide dismutase. The Journal of nutrition. 1992;122(3 Suppl):636-40.

10. Klinman JP. Mechanisms Whereby Mononuclear Copper Proteins Functionalize Organic Substrates. Chemical Reviews. 1996;96(7):2541-62.

11. Telianidis J, Hung YH, Materia S, La Fontaine S. Role of the P-Type ATPases, ATP7A and ATP7B in brain copper homeostasis. Frontiers in Aging Neuroscience. 2013;5.

12. Opsahl W, Zeronian H, Ellison M, Lewis D, Rucker RB, Riggins RS. Role of Copper in Collagen Cross-linking and Its Influence on Selected Mechanical Properties of Chick Bone and Tendon. The Journal of nutrition. 1982;112(4):708-16.

13. Harris ED, Rayton JK, Balthrop JE, Di Silvestro RA, Garcia-de-Quevedo M. Copper and the Synthesis of Elastin and Collagen. Ciba Foundation Symposium 79 - Biological Roles of Copper: John Wiley \& Sons, Ltd.; 1980. p. 163-82.

14. Harris ED. Copper and Iron: A landmark connection of two essential metals. The Journal of Trace Elements in Experimental Medicine. 2001;14(2):207-10.

15. Medeiros D, Jennings D. Role of Copper in Mitochondrial Biogenesis Via Interaction with ATP Synthase and Cytochrome c Oxidase. J Bioenerg Biomembr. 2002;34(5):389-95.

16. Lerner AB. Effect of Ions on Melanin Formation1,2. The Journal of Investigative Dermatology. 1952;18(1):47-52.

17. López-Serrano D, Solano F, Sanchez-Amat A.

Involvement of a novel copper chaperone in tyrosinase activity and melanin synthesis in Marinomonas mediterranea. Microbiology. 2007;153(7):2241-9.

18. Verwilst P, Sunwoo K, Kim JS. The role of copper ions in pathophysiology and fluorescent sensors for the detection thereof. Chem Commun. 2015;51(26):5556-71.

19. Huang X, Atwood CS, Hartshorn MA, Multhaup G, Goldstein LE, Scarpa RC, et al. The A $\beta$ Peptide of Alzheimer's Disease Directly Produces Hydrogen Peroxide through Metal Ion Reduction. Biochemistry. 1999;38(24):7609-16.

20. Opazo C, Huang X, Cherny RA, Moir RD, Roher AE, White AR, et al. Metalloenzyme-like Activity of Alzheimer's Disease $\beta$-Amyloid: Cu-DEPENDENT CATALYTIC
CONVERSION OF DOPAMINE, CHOLESTEROL, AND BIOLOGICAL REDUCING AGENTS TO NEUROTOXIC H2O2. Journal of Biological Chemistry. 2002;277(43):40302-8. 21. Rahimi Y, Goulding A, Shrestha S, Mirpuri S, Deo SK. Mechanism of Copper Induced Fluorescence Quenching of Red Fluorescent Protein, DsRed. Biochemical and biophysical research communications. 2008;370(1):57-61.

22. Mounier S, Zhao H, Garnier C, Roland R. Copper complexing properties of dissolved organic matter: PARAFAC treatment of fluorescence quenching. Biogeochemistry. 2011;106(1):107-16.

23. He G, Zhang X, He C, Zhao X, Duan C. Ratiometric fluorescence chemosensors for copper(II) and mercury(II) based on FRET systems. Tetrahedron. 2010;66(51):9762-8.

24. Mendoza-Espinosa D, Negron-Silva GE, Angeles-Beltran D, Alvarez-Hernandez A, Suarez-Castillo OR, Santillan R.

Copper(ii) complexes supported by click generated mixed NN, NO, and NS 1,2,3-triazole based ligands and their catalytic activity in azide-alkyne cycloaddition. Dalton Transactions. 2014;43(19):706977.

25. Saleem F, Rao GK, Kumar A, Mukherjee G, Singh AK. Half-Sandwich Ruthenium(II) Complexes of Click Generated 1,2,3Triazole Based Organosulfur/-selenium Ligands: Structural and Donor Site Dependent Catalytic Oxidation and Transfer Hydrogenation Aspects. Organometallics. 2013;32(13):3595-603. 26. Struthers H, Spingler B, Mindt TL, Schibli R. "Click-toChelate": Design and Incorporation of Triazole-Containing MetalChelating Systems into Biomolecules of Diagnostic and Therapeutic Interest. Chemistry - A European Journal. 2008;14(20):6173-83.

27. Lau YH, Rutledge PJ, Watkinson M, Todd MH. Chemical sensors that incorporate click-derived triazoles. Chemical Society Reviews. 2011;40(5):2848-66.

28. Ghosh D, Rhodes S, Hawkins K, Winder D, Atkinson A, Ming W, et al. A simple and effective 1,2,3-triazole based "turn-on" fluorescence sensor for the detection of anions. New Journal of Chemistry. 2015;39(1):295-303.

29. Kolb HC, Finn MG, Sharpless KB. Click Chemistry: Diverse Chemical Function from a Few Good Reactions. Angewandte Chemie International Edition. 2001;40(11):2004-21. 30. Xu H-R, Li K, Liu Q, Wu T-M, Wang M-Q, Hou J-T, et al. Dianthracene-cyclen conjugate: the first equal-equivalent responding fluorescent chemosensor for $\mathrm{Pb} 2+$ in aqueous solution. Analyst. 2013;138(8):2329-34.

31. Huang H-J, Fang H-Y, Chir J-L, Wu A-T. Effect of bistriazoles on a ribose-based fluorescent sensor. Luminescence. 2011;26(6):518-22.

32. Hung H-C, Cheng C-W, Ho IT, Chung W-S. Dual-mode recognition of transition metal ions by bis-triazoles chained pyrenes. Tetrahedron Letters. 2009;50(3):302-5.

33. Hung H-C, Cheng C-W, Wang Y-Y, Chen Y-J, Chung W$\mathrm{S}$. Highly Selective Fluorescent Sensors for $\mathrm{Hg} 2+$ and $\mathrm{Ag}+\mathrm{Based}$ on Bis-triazole-Coupled Polyoxyethylenes in $\mathrm{MeOH}$ Solution. Eur J Org Chem. 2009;2009(36):6360-6.

34. Bryant JJ, Lindner BD, Bunz UHF. Water-Soluble Bistriazolyl Benzochalcogendiazole Cycloadducts as Tunable Metal Ion Sensors. The Journal of Organic Chemistry. 2013;78(3):1038-44.

35. Fischer C, Weber E. Bis-calix[4]arene-based podants using the bridge position as a constructive mode of subunit connection. Journal of Inclusion Phenomena and Macrocyclic Chemistry. 2014;79(1):151-60.

36. Hemamalini A, Mohan Das T. Design and synthesis of sugar-triazole low molecular weight gels as mercury ion sensor. New Journal of Chemistry. 2013;37(8):2419-25. 
37. Midya GC, Paladhi S, Bhowmik S, Saha S, Dash J. Design and synthesis of an on-off "click" fluorophore that executes a logic operation and detects heavy and transition metal ions in water and living cells. Organic \& Biomolecular Chemistry. 2013;11(18):305763.

38. Ruan Y-B, Yu Y, Li C, Bogliotti N, Tang J, Xie J. Triazolyl benzothiadiazole fluorescent chemosensors: a systematic investigation of 1,4- or 1,5-disubstituted mono- and bis-triazole derivatives. Tetrahedron. 2013;69(23):4603-8.

39. Shi D-T, Wei X-L, Sheng Y, Zang Y, He X-P, Xie J, et al. Substitution Pattern Reverses the Fluorescence Response of Coumarin Glycoligands upon Coordination with Silver (I). Scientific Reports. 2014;4:4252.

40. Zhang Y-J, He X-P, Hu M, Li Z, Shi X-X, Chen G-R.

Highly optically selective and electrochemically active chemosensor for copper (II) based on triazole-linked glucosyl anthraquinone. Dyes and Pigments. 2011;88(3):391-5.

41. Tang Y-H, Qu Y, Song Z, He X-P, Xie J, Hua J, et al. Discovery of a sensitive $\mathrm{Cu}(\mathrm{ii})$-cyanide "off-on" sensor based on new C-glycosyl triazolyl bis-amino acid scaffold. Organic \& Biomolecular Chemistry. 2012;10(3):555-60.

42. Li K-B, Zang Y, Wang H, Li J, Chen G-R, James TD, et al. Hepatoma-selective imaging of heavy metal ions using a 'clicked' galactosylrhodamine probe. Chemical Communications.

2014;50(79):11735-7.

43. Hrishikesan E, Saravanan C, Kannan P. Bis-TriazoleAppended Azobenzene Chromophore for Selective Sensing of Copper(II) Ion. Industrial \& Engineering Chemistry Research. 2011;50(13):8225-9.

44. Pirali T, Gatti S, Di Brisco R, Tacchi S, Zaninetti R, Brunelli E, et al. Estrogenic Analogues Synthesized by Click Chemistry. ChemMedChem. 2007;2(4):437-40.

45. Hashmi ASK, Häffner T, Rudolph M, Rominger F. Gold Catalysis: Domino Reaction of En-Diynes to Highly Substituted Phenols. Chemistry - A European Journal. 2011;17(29):8195-201. 46. Kumar A, Pandey PS. Anion Recognition by 1,2,3Triazolium Receptors: Application of Click Chemistry in Anion Recognition. Organic Letters. 2008;10(2):165-8.

47. Lee S, Hua Y, Park H, Flood AH. Intramolecular Hydrogen Bonds Preorganize an Aryl-triazole Receptor into a Crescent for Chloride Binding. Organic Letters. 2010;12(9):2100-2. 48. Wang Y, Bie F, Jiang H. Controlling Binding Affinities for Anions by a Photoswitchable Foldamer. Organic Letters. 2010;12(16):3630-3.

49. He G, Zhao Y, He C, Liu Y, Duan C. "Turn-On" Fluorescent Sensor for $\mathrm{Hg} 2+$ via Displacement Approach. Inorganic Chemistry. 2008;47(12):5169-76.

50. Guha PM, Phan H, Kinyon JS, Brotherton WS, Sreenath

K, Simmons JT, et al. Structurally Diverse Copper(II) Complexes of Polyaza Ligands Containing 1,2,3-Triazoles: Site Selectivity and Magnetic Properties. Inorganic Chemistry. 2012;51(6):3465-77. 51. Urankar D, Pinter B, Pevec A, De Proft F, Turel I, Košmrlj J. Click-Triazole N2 Coordination to Transition-Metal Ions Is Assisted by a Pendant Pyridine Substituent. Inorganic Chemistry. 2010;49(11):4820-9.

52. Liu M-X, Wei T-B, Lin Q, Zhang Y-M. A novel 5mercapto triazole Schiff base as a selective chromogenic chemosensor for $\mathrm{Cu} 2+$. Spectrochimica acta Part A, Molecular and biomolecular spectroscopy. 2011;79(5):1837-42.

53. Delsignore M, Maaser HE, Petrucci S. Molecular relaxation of lithium salts in 2-methyltetrahydrofuran at 25.degree.C. The Journal of Physical Chemistry. 1984;88(11):2405-11.

54. McIntyre JF, Foley RT, Brown BF. Ultraviolet spectra of aluminum salt solutions. Inorganic Chemistry. 1982;21(3):1167-72.
55. Mahapatra AK, Hazra G, Mukhopadhyay SK, Mukhopadhyay AR. A new selective turn-on fluorogenic dipodalcobalt(II) ensemble probe for nitrite ion detection and live cell imaging. Tetrahedron Letters. 2013;54(9):1164-8.

56. Lin T-P, Chen C-Y, Wen Y-S, Sun S-S. Synthesis, Photophysical, and Anion-Sensing Properties of

Quinoxalinebis(sulfonamide) Functionalized Receptors and Their Metal Complexes. Inorganic Chemistry. 2007;46(22):9201-12.

57. Aboubakr H, Brisset H, Siri O, Raimundo J-M. Highly

Specific and Reversible Fluoride Sensor Based on an Organic Semiconductor. Analytical Chemistry. 2013;85(20):9968-74.

58. Shellaiah M, Rajan YC, Lin H-C. Synthesis of novel triarylamine-based dendrimers with N4,N6-dibutyl-1,3,5-triazine4,6-diamine probe for electron/energy transfers in H-bonded donoracceptor-donor triads and as efficient $\mathrm{Cu} 2+$ sensors. Journal of Materials Chemistry. 2012;22(18):8976-87.

59. Thakur A, Mandal D, Ghosh S. A triazole based triferrocene derivative as a multiresponsive chemosensor for $\mathrm{Hg}$ (II) ion and a redox chemosensor for H2PO4- ion. Journal of Organometallic Chemistry. 2013;726:71-8.

60. Kumar A, Kumar V, Diwan U, Upadhyay KK. Highly sensitive and selective naked-eye detection of $\mathrm{Cu} 2+$ in aqueous medium by a ninhydrin-quinoxaline derivative. Sensors and Actuators B: Chemical. 2013;176:420-7.

61. Acceptability aspects: Taste, odour and appearance. Guidelines for Drinking Water. 4th ed: World Health Organization; 2011. p. 224-5.

62. Benesi HA, Hildebrand JH. A Spectrophotometric Investigation of the Interaction of Iodine with Aromatic Hydrocarbons. Journal of the American Chemical Society. 1949;71(8):2703-7.

63. Mallick A, Haldar B, Chattopadhyay N. Spectroscopic Investigation on the Interaction of ICT Probe 3-Acetyl-4-oxo-6,7dihydro-12H Indolo-[2,3-a] Quinolizine with Serum Albumins. The Journal of Physical Chemistry B. 2005;109(30):14683-90.

64. Sarkar D, Mahata A, Das P, Girigoswami A, Ghosh D, Chattopadhyay N. Deciphering the perturbation of serum albumins by a ketocyanine dye: A spectroscopic approach. Journal of Photochemistry and Photobiology B: Biology. 2009;96(2):136-43.

65. Burai TN, Panda D, Datta A. Fluorescence enhancement of epicocconone in its complexes with cyclodextrins. Chemical Physics Letters. 2008;455(1-3):42-6.

66. Young DC. Appendix A: Software Packages.

Computational Chemistry: John Wiley \& Sons, Inc.; 2001. p. 32259.

67. Frisch MJ, Trucks GW, Schlegel HB, Scuseria GE, Robb MA, Cheeseman JR, et al. Gaussian 09. Wallingford, CT, USA: Gaussian, Inc.; 2009. 